\title{
Elasmobrânquios capturados pela pesca artesanal na costa sul do Paraná e norte de Santa Catarina, Brasil.
}

\author{
Luciano Costa $^{1} \&$ Paulo de Tarso da Cunha Chaves $^{2}$ \\ Biota Neotropica v6 (n3) -http://www.biotaneotropica.org.br/v6n3/pt/abstract?article+bn02706032006 \\ Recebido: 25/09/2005 \\ Publicado: 16/11/2006
}

Depto. de Zoologia, Universidade Federal do Paraná - Caixa Postal 19020, CEP 81531-980 Curitiba, PR, Brasil. 1tetragonisca@yahoo.com.br, ${ }^{2}$ ptchaves@ufpr.br

\begin{abstract}
Costa, L. and Chaves, P. T. C. Elasmobranchs caught by artisanal fishing in the south cost of Parana State and north cost of Santa Catarina State, Brazil. Biota Neotrop. Sep/Dec 2006 vol. 6, no. 3 http://www.biotaneotropica.org.br/v6n3/pt/ abstract?article+bn02706032006 ISSN 1676-0603

This study was done in the South coast of Parana State and North coast of Santa Catarina State, Brazil, in two artisanal fishermen communities. Between July, 2001 and March, 2003 the fishing activities were observed aiming to: report the elasmobranchs caught species; report which species are commercialized; observe the seasonal occurrence of the species in the landings; estimate the frequency of capture by different fishing gears; and infer about the reproductive biology of the species. During the studied period were captured: Carcharhinus falciformis, Galeocerdo cuvier, Rhizoprionodon lalandii, R. porosus, Sphyrna lewini, S. zygaena, Squatina guggenheim, Narcine brasiliensis, Rhinobatos percellens, Zapteryx brevirostris, Rioraja agassizii, Dasyatis americana, D. guttata, D. hipostigma, Gymnura altavela, Myliobatis goodei, Rhinoptera bonasus and $R$. brasiliensis. It was observed that all sharks and only two ray species $(R$. percellens and Z. brevirostris) are commercialized. In the landings, elasmobranchs were more frequent during winter and spring. Most catches were done by gillnets, while just a few captures were done by shrimp trawls. The data indicated that the studied area is used by G. cuvier, R. lalandii, R. porosus, S. lewini, N. brasiliensis and R. agassizii to give birth; by all species for growing; and during the gestation of $R$. percellens and $Z$. brevirostris. It is suggested that actions aiming to protect the species must be taken, without harming and conflicts for the fishermen communities.
\end{abstract}

Key words: rays, sharks, skates, Chondrichthyes, reproductive biology.

\section{Resumo}

Costa, L. and Chaves, P. T. C. Elasmobrânquios capturados pela pesca artesanal na costa sul do Paraná e norte de Santa Catarina, Brasil. Biota Neotrop. Sep/Dec 2006 vol. 6, no. 3 http://www.biotaneotropica.org.br/v6n3/pt/ abstract?article+bn02706032006 ISSN 1676-0603

O presente estudo foi realizado no litoral entre a divisa dos Estados do Paraná e Santa Catarina, em duas comunidades pesqueiras artesanais que integram os municípios de Guaratuba (PR) e Itapoá (SC). Foram acompanhadas as atividades pesqueiras das comunidades, entre julho de 2001 e março de 2003, com o objetivo de: listar as espécies de elasmobrânquios capturadas pelas comunidades em questão; avaliar o uso comercial das espécies; observar a ocorrência sazonal das espécies nos desembarques; estimar a freqüência relativa de captura por aparelho de pesca; e inferir sobre a biologia reprodutiva das espécies. Durante o período estudado foram capturados: Carcharhinus falciformis, Galeocerdo cuvier, Rhizoprionodon lalandii, R. porosus, Sphyrna lewini, S. zygaena, Squatina guggenheim, Narcine brasiliensis, Rhinobatos percellens, Zapteryx brevirostris, Rioraja agassizii, Dasyatis americana, D. guttata, D. hipostigma, Gymnura altavela, Myliobatis goodei, Rhinoptera bonasus e R. brasiliensis. Quanto à comercialização das espécies, foi observado que todos os tubarões capturados na área de estudo são comercializados, dentre as raias, apenas Rhinobatos percellens e Zapteryx brevirostris. Nos desembarques, a ocorrência de elasmobrânquios foi maior durante o inverno e a primavera. A maioria das capturas ocorreu com redes de emalhe, o arrasto camaroneiro pouco capturou. Os dados do presente trabalho indicaram a utilização da área estudada para o parto das espécies G. cuvier, $R$. lalandii, $R$. porosus, S. lewini, $N$. brasiliensis e R. agassizii; para o crescimento de todas as espécies amostradas; e para a gestação de $R$. percellens e Z. brevirostris. É sugerido que medidas que visem a proteger as espécies sejam tomadas, sem trazer prejuízos e conflitos para as comunidades de pescadores.

Palavras-chave: raias, tubarões, cações, Chondricthyes, biologia reprodutiva. 


\section{Introdução}

Os peixes cartilaginosos são comumente capturados em várias artes de pescarias, como nos arrastos de fundo, nos espinhéis e nas redes de emalhe, intencionalmente ou como fauna acompanhante. No entanto, dados sobre o desembarque pesqueiro são escassos e muitas espécies encontram-se ameaçadas, devido a suas características de crescimento lento, maturação sexual tardia, vida longa, baixa fecundidade e baixa mortalidade natural (Stevens et al. 2000).

No litoral correspondente à divisa entre os Estados do Paraná e Santa Catarina, existem duas comunidades pesqueiras artesanais, integrantes dos municípios de Guaratuba (PR) e Itapoá (SC). Estas comunidades operam na borda entre os dois estados, explorando áreas de até 20 m de profundidade, até $20 \mathrm{~km}$ de distância da costa (Chaves \& Robert 2003). As embarcações mais comuns são canoas de madeira (aproximadamente 60), motorizadas, com potência entre 11 e $24 \mathrm{HP}$, equipadas com redes de emalhe e redes de arrasto camaroneiro (Robert 2004).

Poucos estudos sobre elasmobrânquios foram realizados no litoral paranaense (Barletta \& Corrêa 1989, Barletta \& Corrêa 1991, Charvet 1995a,b). No entanto, muitas espécies deste grupo foram citadas em levantamentos ictiofaunísticos e de produção pesqueira (Loyola e Silva \& Nakamura 1975, Corrêa 1987, Maehama \& Corrêa 1987, Corrêa e Maehama 1988, Godefroid 1997, Abilhôa 1998, Chaves \& Corrêa 1998, Chaves et al. 2000).

Paiva (1997) relatou que entre os anos de 1980 e 1994, dentre os principais recursos pesqueiros (estuarinos e marinhos) do Estado do Paraná, 6,4\% da produção total de pescados, explorados pela pesca artesanal, foram constituídos por elasmobrânquios. Este valor foi superior ao das capturas de importantes teleósteos, como as pescadas (5,9\%) e as tainhas (5,1\%), sendo o camarão-sete-barbas o principal recurso explorado (30,5\% das capturas). No mesmo período, no Estado de Santa Catarina, os elasmobrânquios significaram $12,7 \%$ das capturas da pesca artesanal, valor similar ao de camarões-sete-barbas (10,4\%), corvinas (14,5\%) e tainhas (13,4\%).

O presente estudo tem como objetivos: relatar as espécies de elasmobrânquios capturadas pelas comunidades em questão; avaliar o uso comercial das espécies; observar a ocorrência das espécies nos desembarques; estimar a freqüência relativa de captura de elasmobrânquios por aparelho de pesca; e inferir sobre a biologia reprodutiva das espécies capturadas. Deste modo, disponibilizam-se dados para programas de administração pesqueira na costa sul do Estado do Paraná e norte do Estado de Santa Catarina, ajudando a diminuir a lacuna existente no conhecimento sobre elasmobrânquios na região.

\section{Material e Métodos}

Entre julho de 2001 e março de 2003, foram realizadas 49 amostragens nas comunidades de Brejatuba (255' S; $\left.48^{\circ} 33^{\prime} \mathrm{W}\right)$, município de Guaratuba (PR), e Barra do Saí (2600' S; 48³6’ W), município de Itapoá (SC), durante todos os meses deste período. Nas visitas às comunidades, foram observados os desembarques diários, os quais ocorreram, em geral, entre 9 e 14 horas. Todas as artes de pescarias foram observadas, sendo mais freqüentes o fundeio (pescaria realizada com rede de emalhe fixa ao fundo) e o arrasto camaroneiro.

A identificação taxonômica seguiu Figueiredo (1977), Castro (1983), Compagno (1984), Gadig (2001), Froese \& Pauly (2003) e Santos \& Carvalho (2004). A nomenclatura foi atualizada de acordo com Menezes et al. (2003). Os nomes populares das espécies correspondem aos utilizados pelos pescadores das comunidades estudadas. Espécimes representativos de todas as espécies (exceto Dasyatis guttata) foram depositados na coleção do Museu de História Natural Capão da Imbuia - Curitiba, Paraná.

A utilização das espécies pelas comunidades pesqueiras foi avaliada pela observação direta dos locais de venda, bem como por diálogos com membros das comunidades.

A estimativa da proporção de captura, por aparelho de pesca, foi realizada a partir do número de indivíduos capturados, com determinado equipamento, em relação ao total de indivíduos capturados, no período sazonal, e expressa em percentagem.

Na avaliação da ocorrência das espécies nos desembarques pesqueiros, foi considerado o número de dias em que cada espécie foi observada, em relação ao total de dias amostrados durante a estação considerada.

No campo, foram tomados dados de comprimento total (CT) e largura do disco (LD - nas raias), em centímetros, com trena. Tomaram-se também dados morfológicos dos tratos reprodutores, descritos a seguir. Os estágios de desenvolvimento reprodutivo foram inferidos de acordo com Castro (1983) e Hazin et al. (2001). Desta forma, os neonatos foram reconhecidos por apresentar cicatriz umbilical aberta (Carcharhinidae e Sphyrnidae) ou saco vitelínico interno (Narcinidae). Foram considerados jovens: fêmeas que não demonstravam, macroscopicamente, atividade vitelogênica (apresentavam ovários com coloração esbranquiçada); machos com clásperes flácidos (não calcificados) ou semiflácidos (não totalmente calcificados). Adultos foram considerados: fêmeas com evidência macroscópica de vitelogênese (ovários com folículos evidentes e amarelos); machos com clásperes rígidos (totalmente calcificados). A calcificação dos clásperes foi analisada manualmente, observando a flexibilidade. Grávidas foram consideradas as fêmeas adultas que continham embriões no interior dos ovidutos. 
Quando possível, foram tomados dados sobre o desenvolvimento dos embriões. O número de indivíduos examinados não corresponde ao total das capturas realizadas nas comunidades estudadas, mas apenas uma amostra.

A análise dos dados foi realizada agrupando-se os meses em estações climáticas: verão (dezembro, janeiro e fevereiro); outono (março, abril e maio); inverno (junho, julho e agosto); e primavera (setembro, outubro e novembro).

As espécies Rhinoptera bonasus e R. brasiliensis foram consideradas como Rhinoptera spp., visto que ambas ocorreram nos desembarques, mas apenas uma parte da amostra foi corretamente identificada.

\section{Resultados e discussão}

Dezoito espécies de elasmobrânquios, pertencentes a nove famílias, integraram as capturas durante o período de estudo (Tabela 1). Os tubarões foram representados por sete espécies de três famílias, enquanto as raias por onze espécies de seis famílias. Um total de 364 indivíduos foi medido (CT ou LD). Destes, 339 foram analisados quanto à biologia reprodutiva.

Destacou-se a predominância de espécies de pequeno porte, sendo que indivíduos de espécies de grande porte ocorreram em número pequeno e apenas ocasionalmente, em geral na forma jovem. É possível que a predominância de indivíduos de pequeno porte seja devida às características da região estudada (plataforma continental rasa), bem como devido aos aparelhos de pesca e embarcações utilizadas, os quais não são adequados para a captura de exemplares de grande porte. Porém, Russ (1991) relata que a diminuição em abundância, especialmente das maiores classes de tamanho, é característica de populações exploradas de peixes.

Existe uma ampla evidência histórica de declínio das populações de peixes cartilaginosos ao redor do mundo, incluindo o Brasil (Stevens et al. 2000). Membros mais antigos das comunidades pesqueiras, estudadas no presente trabalho, informaram que seus pais e avós comumente capturavam grandes tubarões, próximo à praia. Fotografias foram apresentadas como evidência, do relatado.

Loyola e Silva \& Nakamura (1975) relataram que dentre as principais espécies de pescados explorados pela pesca artesanal no litoral do Paraná, estava o cação mangona, Carcharias taurus. Durante o presente estudo, nenhum exemplar desta espécie foi desembarcado; apenas uma citação de captura, fora dos dias amostrados (primavera), foi notificada pelos pescadores. Esta espécie apresenta-se ameaçada de extinção (IUCN 2004). Além desta, dentre as espécies aqui citadas, Galeocerdo cuvier, Rhizoprionodon lalandii, Sphyrna lewini, S. zygaena, Squatina guggenheim, Rhinoptera brasiliensis e Dasyatis guttata também estão ameaçadas (IUCN 2004).
Foi observado que todos os tubarões capturados na área de estudo são comercializados. Dentre as raias, apenas Rhinobatos percellens e Zapteryx brevirostris são comercializadas. Aparentemente não há espécies-alvo e indivíduos de todas as espécies de tubarões, bem como as duas de raias, citadas anteriormente, são vendidos com o nome "cação" (em postas ou filés). Apenas ocasionalmente observou-se a comercialização das nadadeiras dos tubarões, para atravessadores. Na maioria das vezes, as nadadeiras foram descartadas.

A utilização de diferentes aparelhos de pesca, pelas comunidades, permitiu verificar a relação entre os aparelhos utilizados e a captura de elasmobrânquios (Figura 1). A maioria dos indivíduos analisados durante o inverno, a primavera e o verão foram capturados com redes de emalhe de $16 \mathrm{~cm}$ entre nós opostos. A rede de malha de $7 \mathrm{~cm}$ foi também expressiva na amostra do verão. Durante o outono, a maior parte dos exemplares analisados foi capturada com rede de emalhe de $11 \mathrm{~cm}$ (nós opostos). Apenas uma pequena parte da amostragem foi obtida com arrasto camaroneiro.

Nos desembarques, a ocorrência de elasmobrânquios foi maior durante o inverno e a primavera, e menor durante o verão e o outono (Figura 2). A menor ocorrência de espécies de elasmobrânquios durante o período do verão, comparativamente a outras estações, pode ser relacionada ao elevado uso do arrasto camaroneiro, que objetivou a captura de camarão-sete-barbas, em detrimento do uso de redes de emalhe de fundo. Um grande esforço na captura de camarões, durante este período, é justificado pela chegada de turistas (consumidores) à região. A captura de peixes cartilaginosos neste período ocorreu concomitantemente à de teleósteos como, salteira (Oligoplites saliens), betara (Menticirrhus spp.) e outras espécies, principais objetivos das pescarias com redes de emalhe. Poucas embarcações tiveram como objetivo a captura de cações. No entanto, mesmo que elasmobrânquios não sejam desembarcados todos os dias, é possível que algumas espécies sejam ocasionalmente capturadas em grande número.

Durante o outono, outra estação de baixa ocorrência de elasmobrânquios, também houve grande uso do arrasto, objetivando a captura do camarão-branco, mesmo tratandose do período de defeso da pesca com arrasto. Foi observado que para as capturas de camarão branco, durante o outono, utilizou-se também o caceio, com redes de malha 5 e $6 \mathrm{~cm}$ entre nós opostos. A dedicação dos pescadores na captura desta espécie de camarão, em detrimento dos peixes, justifica-se pelo seu alto valor de comercialização.

A maior ocorrência de elasmobrânquios, durante os períodos do inverno e primavera, está relacionada ao tipo de aparelhos de pesca utilizados pelas comunidades. No caso do inverno, graças à pesca direcionada ao linguado (Paralichthys spp.), empregam-se redes de emalhe de $16 \mathrm{~cm}$ entre nós opostos. Durante a primavera, predominam as 
Tabela 1. Espécies capturadas pela pesca artesanal, entre o litoral sul do Paraná e norte de Santa Catarina. Os nomes entre parênteses correspondem à denominação popular das espécies. $N=$ número amostral; $C T=$ comprimento total; LD = largura do disco. Nas raias Rhinobatidae e Narcinidae são apresentados os dados de CT; para as demais são apresentados os dados de LD. Rhinoptera spp = R. bonasus e R. brasiliensis.

Table 1. Species caught by artisanal fishery in the south coast of Parana State and north coast of Santa Catarina State. The names between brackets are the common names of the species. $N=$ sample number; $C T=$ total length; $L D=$ width of the disk. The data of Rhinobatidae and Narcinidae rays are total length; in the other rays the width of de disk was measured. Rhinoptera spp $=R$. bonasus and R. brasiliensis.

\begin{tabular}{|c|c|c|c|}
\hline Espécie & n & $\begin{array}{c}\text { CT ou LD } \\
\text { (mínimo - máximo) }\end{array}$ & $\begin{array}{c}\text { CT ou LD } \\
\text { (média - desvio padrão) }\end{array}$ \\
\hline \multicolumn{4}{|l|}{ CARCHARHINIDAE } \\
\hline Carcharhinus falciformis (cação-figo-branco) & 3 & $95,0-111,0$ & $103,7-8,1$ \\
\hline Galeocerdo cuvier (tintureira) & 4 & $79,0-174,0$ & $129,9-41,3$ \\
\hline Rhizoprionodon lalandii (cação-corpo-duro) & 55 & $31,8-76,8$ & $59,3-16,9$ \\
\hline Rhizoprionodon porosus (cação-corpo-duro, charuto) & 12 & $38,0-59,0$ & $44,6-5,8$ \\
\hline \multicolumn{4}{|l|}{$\begin{array}{l}\text { SPHYRNIDAE } \\
\end{array}$} \\
\hline Sphyrna lewini (cação-martelo, cambeva) & 6 & $54,4-75,7$ & $65,6-9,2$ \\
\hline Sphyrna zygaena (cação-martelo, cambeva) & 25 & $78,0-118,4$ & $93,1-15,8$ \\
\hline \multicolumn{4}{|l|}{ SQUATINIDAE } \\
\hline Squatina guggenheim (cação-anjo) & 6 & $71,2-99,0$ & $82,2-11,1$ \\
\hline \multicolumn{4}{|l|}{ NARCINIDAE } \\
\hline Narcine brasiliensis (treme-treme) & 32 & $10,4-47,8$ & $33,0-11,0$ \\
\hline \multicolumn{4}{|l|}{ RHINOBATIDAE } \\
\hline Rhinobatos percellens ("cação"-viola) & 87 & $49,1-102,0$ & $74,2-11,4$ \\
\hline $\begin{array}{l}\text { Zapteryx brevirostris ("cação"-bandolim, piçudinho) } \\
\text { RAJIDAE }\end{array}$ & 61 & $43,5-54,0$ & $48,2-2,4$ \\
\hline Rioraja agassizii (raia-emplastro) & 38 & $33,4-57,1$ & $46,2-5,7$ \\
\hline \multicolumn{4}{|l|}{ DASYATIDAE } \\
\hline Dasyatis americana (raia-manteiga) & 2 & $36,8-64,5$ & $50,6-19,6$ \\
\hline Dasyatis guttata (raia-chicote) & 3 & $53,0-67,5$ & $62,0-7,9$ \\
\hline Dasyatis hipostigma (raia-manteiga) & 7 & $30,6-45,5$ & $35,1-5,1$ \\
\hline \multicolumn{4}{|l|}{ GYMNURIDAE } \\
\hline Gymnura altavela (raia-jereva) & 5 & $41,2-70,5$ & $57,9-12,9$ \\
\hline \multicolumn{4}{|l|}{ MYLIOBATIDAE } \\
\hline Myliobatis goodei (raia-morcego) & 3 & $29,8-38,8$ & $32,9-5,1$ \\
\hline Rhinoptera spp. (raia-cachorro) & 15 & $49,0-91,6$ & $61,4-12,3$ \\
\hline Total & 364 & & \\
\hline
\end{tabular}

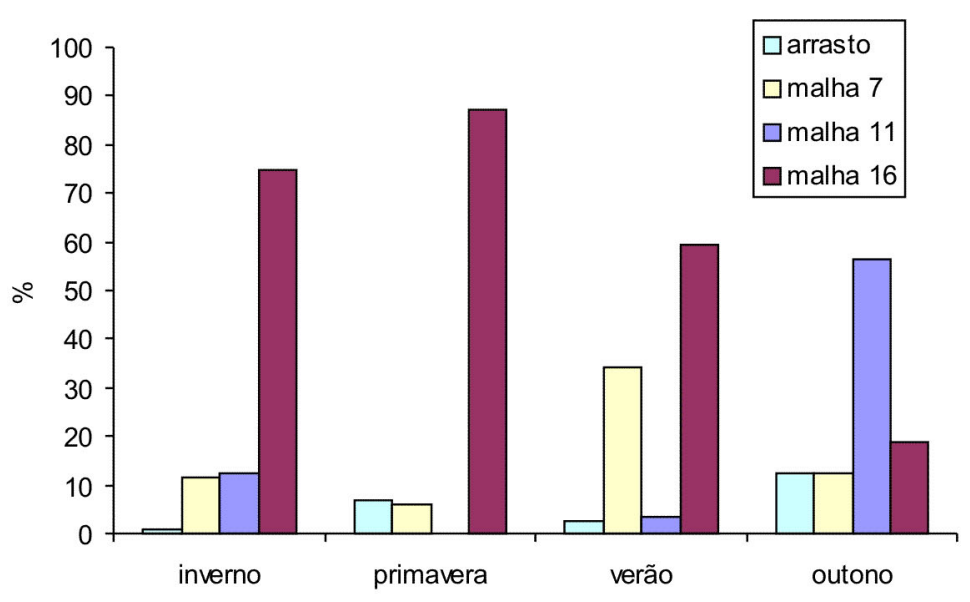

Figura 1. Freqüencia relativa de captura de elasmobrânquios por aparelho de pesca.

Figure 1. Elasmobranchs relative frequency of capture by different fishing gears. 

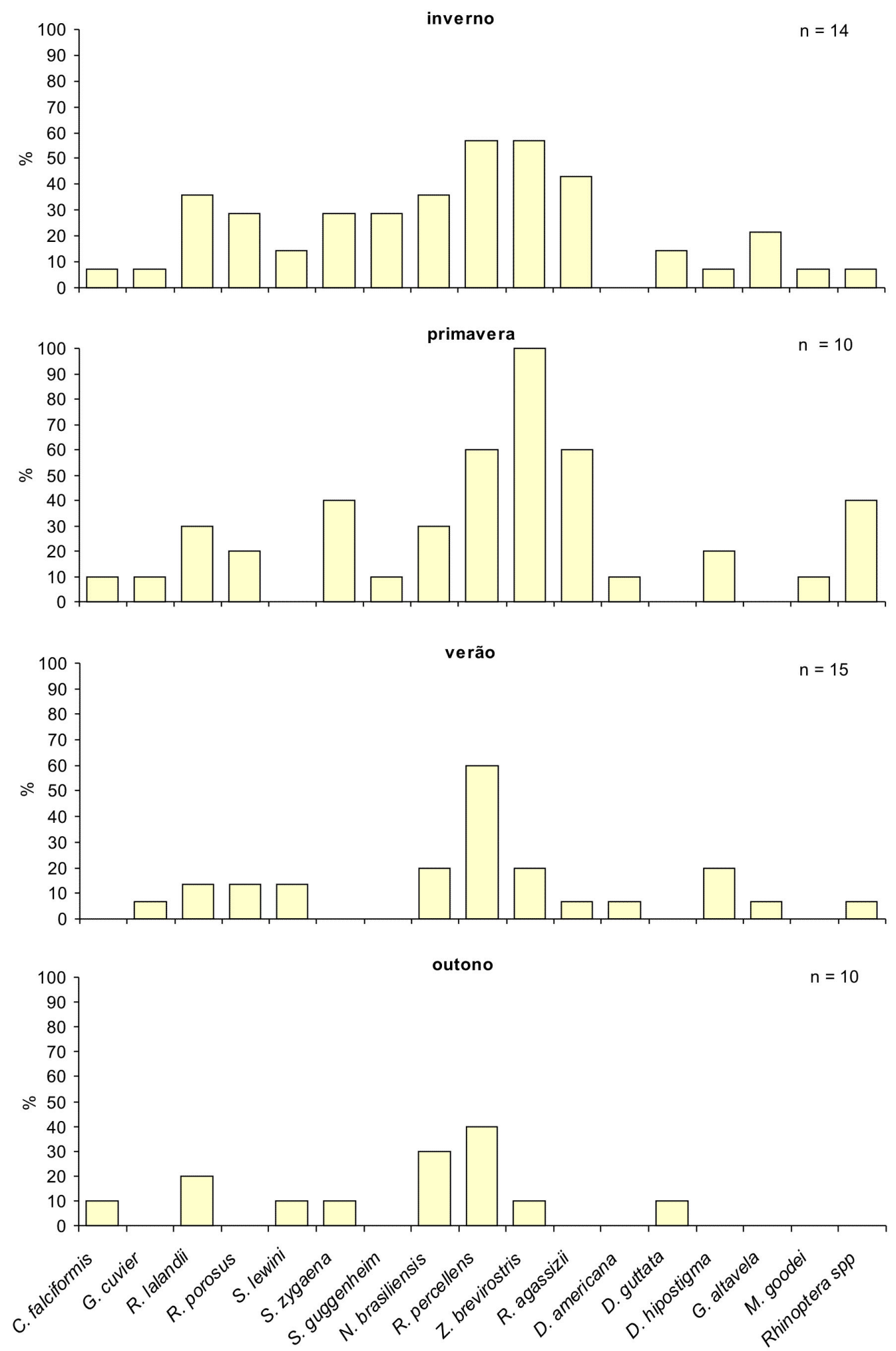

Figura 2. Freqüência das espécies nos dias de desembarques observados. No canto superior direito: número (n) de dias amostrados durante o periodo sazonal.

Figure 2. Frequency of the species in the days of observed landings. At the right superior corner: number (n) of days sampled during the seasonal period. 

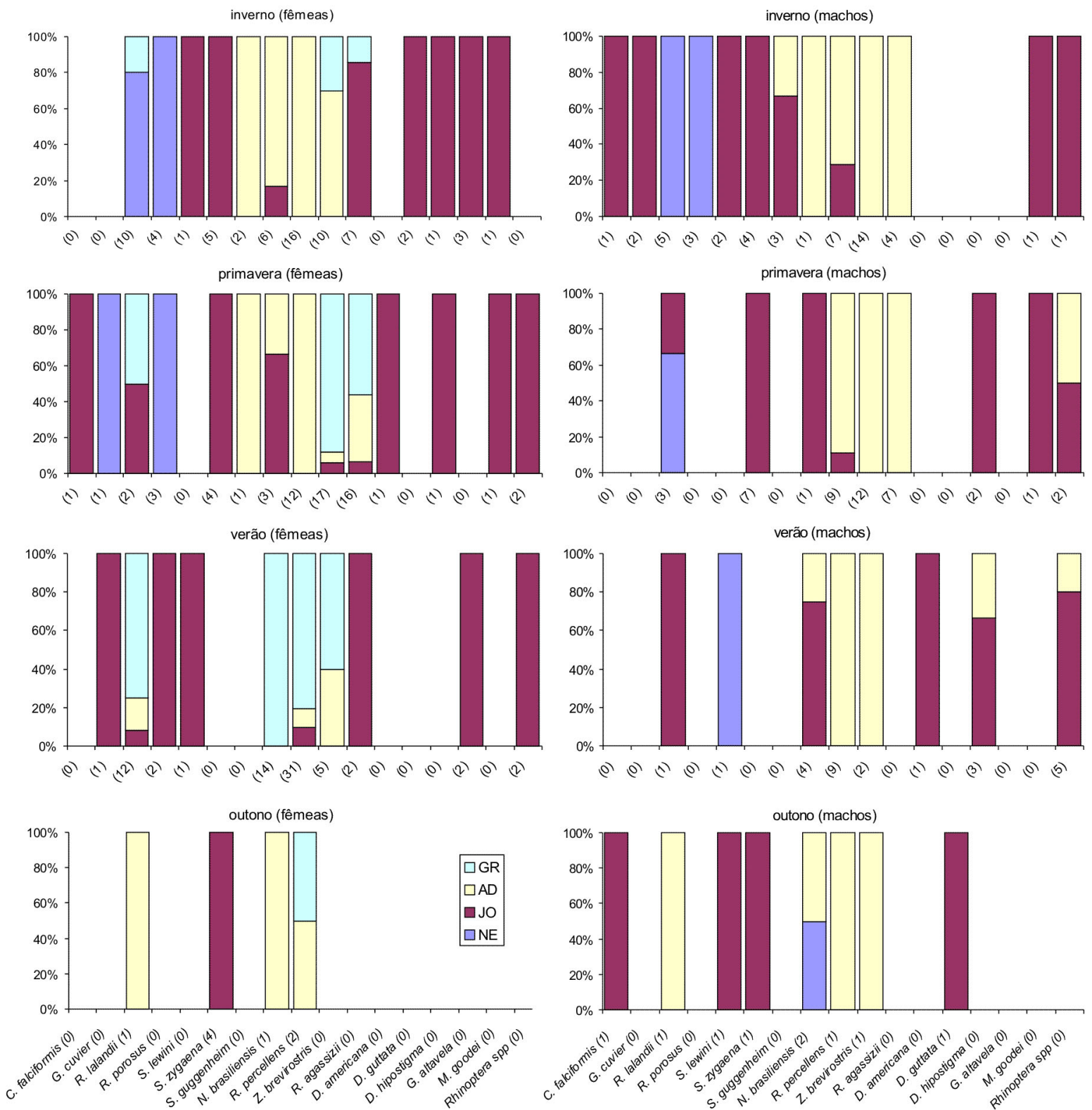

Figura 3. Freqüencia relativa dos estágios de desenvolvimento reprodutivo. Legenda: $G R=$ fêmeas grávidas, $A D=$ adultos, $J O=j o v e n s, N E$ = neonatos. Entre parênteses é indicado o número de exemplares analisados quanto à biologia reprodutiva.

Figure 3. Relative frequency of the reproductive development stages. Legend: $G R=$ pregnant females, $A D=$ adults, JO $=y$ oung, $N E=$ newborn. The numbers between brackets are the numbers of specimens analyzed about the reproductive biology. 
pescarias com redes de emalhe, objetivando a captura de peixes. De acordo com Robert (2004), nesta estação, os pescadores objetivam a captura de corvinas (Micropogonias furnieri), bagres (Genidens barbus), pescadas (Cynoscion spp.), além de cações (Carcharhinidae, Sphyrnidae e Squatinidae) e raias (Rhinobatidae). Desta forma, a variação sazonal da ocorrência de elasmobrânquios, nas pescarias das comunidades estudadas, pode estar associada às modalidades de pesca utilizadas durante os diferentes períodos sazonais, além de possíveis movimentos migratórios das espécies.

A baixa ocorrência de elasmobrânquios nas pescarias de arrasto camaroneiro pode estar associada à pequena potência das embarcações (11 a 24 hp), o que possibilitaria a fuga da maioria das espécies. A maior eficiência das redes de emalhe de $16 \mathrm{~cm}$ entre nós opostos está provavelmente relacionada ao tamanho corporal das espécies. Experimentos de seletividade de pesca poderiam corroborar esta hipótese.

Ao longo dos períodos sazonais observados, a espécie $C$. falciformis foi capturada em baixa freqüência e não ocorreu durante o verão (Figura 2). Todos os exemplares amostrados eram jovens (Figura 3). De acordo com Compagno (1984), C. falciformis é ocasional em águas costeiras e, mesmo agregados de jovens, são encontrados principalmente longe da costa.

Galeocerdo cuvier foi também pouco freqüente e não foi observado durante o outono (Figura 2). Uma fêmea neonata foi observada durante a primavera, indicando um possível período de parto. Os demais indivíduos capturados eram jovens (Figura 3). Compagno (1984) relata que G. cuvier é uma espécie costeira e insular; seu parto ocorre durante a primavera e o verão. Embora esta espécie não tenha sido muito freqüente nas capturas das comunidades pesqueiras estudadas, é evidente que a área de estudo é utilizada para o parto e o crescimento de jovens.

Rhizoprionodon lalandii, assim como a maioria das espécies, foi mais freqüente nos desembarques do inverno e da primavera (Figura 2). Nestas estações, as capturas foram constituídas predominantemente de neonatos, além de fêmeas grávidas em fim de gestação (embriões com 30,6 cm de CT, em média) (Figura 3). Indivíduos jovens de ambos os sexos foram também capturados na primavera (Figura 3). Durante o verão, embora $R$. lalandii tenha sido pouco freqüente (Figura 2), em um dos dias de amostragem, um grande número de indivíduos foi capturado, representando a maior parte da amostra desta estação. Destes exemplares, fêmeas grávidas (em início de gestação, com embriões pouco desenvolvidos) foram maioria, uma pequena parcela era de fêmeas adultas (não grávidas) e de jovens (ambos os sexos) (Figura 3). Durante o outono, apenas uma fêmea adulta e um macho adulto foram observados (Figura 3). As informações do presente estudo sugerem que as fêmeas grávidas de $R$. lalandii utilizam a área estudada para a realização do parto, durante o inverno e o início da primavera. Durante o verão, a gestação encontra-se em estágio inicial ou intermediário. Estes dados são semelhantes aos de Ferreira (1988), na região de Barra de Guaratiba, RJ, onde as fêmeas grávidas aproximam-se da costa durante o inverno, para parir seus filhotes; copulam, iniciam nova gestação e afastam-se da costa, retornando no próximo inverno para novo parto.

Rhizoprionodon porosus foi menos freqüente que $R$. lalandii. Durante o inverno e a primavera, quando a espécie ocorreu em maior freqüência (Figura 2), as capturas foram constituídas de neonatos de ambos os sexos (Figura 3). No verão, apenas fêmeas jovens foram observadas (Figura 3). Os dados do presente estudo, sobre $R$. porosus, são também semelhantes aos obtidos por Ferreira (1988) na região de Barra de Guaratiba, RJ, onde as fêmeas grávidas aproximam-se da costa durante o inverno, para parir seus filhotes. No entanto, nenhuma fêmea grávida foi observada no presente trabalho.

Sphyrna lewini foi pouco freqüente nos desembarques e não foi observado durante a primavera (Figura 2). Indivíduos jovens foram observados no inverno, no verão e no outono (Figura 3 ). Um macho neonato foi capturado durante o verão (Figura 3) e durante o fim da primavera (novembro) foi relatada a captura de uma fêmea grávida. Através da análise de fotografias feitas pelos pescadores, constatou-se que a fêmea media cerca de 2,8 m de CT e possuía, no mínimo, cinco embriões com tamanho de aproximadamente 50 a $60 \mathrm{~cm}$ de CT. O tamanho dos embriões é semelhante ao relatado por Compagno (1984), como sendo o tamanho em que os filhotes nascem. Deste modo, é provável que estes filhotes nasceriam durante o verão. Estes dados indicam a utilização da área para o parto no período do verão. De acordo com Hazin et al. (2001) o parto de $S$. lewini, no nordeste do Brasil, também ocorre durante o verão (dezembro a fevereiro).

Sphyrna zygaena foi o tubarão mais freqüente nas capturas da primavera (Figura 2). Foi também um dos mais freqüentes no inverno e ausente no verão. Todos os exemplares analisados eram jovens (Figura 3), de ambos os sexos. De acordo com Gadig (2001), S. zygaena é a espécie mais comum do gênero, nas regiões sudeste e sul. Isto, provavelmente, devido a sua tolerância a águas temperadas (Compagno 1984). É evidente que indivíduos jovens utilizam a área estudada, pelo menos, durante os períodos de outono a primavera.

A espécie Squatina guggenheim foi freqüentemente observada apenas durante o inverno. Na primavera foi rara e nas demais estações a espécie não foi observada (Figura 2). Fêmeas adultas, um macho adulto e machos jovens foram observados no inverno. Durante a primavera, apenas uma fêmea adulta foi observada (Figura 3). Vooren \& Silva (1991) relataram que, no Estado do Rio Grande do Sul, parte da população desta espécie migra na primavera para águas rasas, onde fêmeas grávidas realizam o parto e jovens ocorrem ao longo do ano. No presente estudo, não foram observadas fêmeas grávidas e os jovens observados eram maiores (CT médio $=71,7 \mathrm{~cm}$ ) que o tamanho de nascimento, cerca de 25 cm, de acordo com Vooren \& Silva (1991). 
Dentre as raias, Narcine brasiliensis apresentou freqüência de observação semelhante ao longo das estações, sendo menos freqüente no verão (Figura 2). No entanto, durante o verão foi obtido o maior número de exemplares examinados quanto à biologia reprodutiva. Isso foi possível devido ao fato de, em alguns acompanhamentos de desembarque, as redes serem trazidas para a despesca em terra e apresentarem um grande número de exemplares desta espécie. Como se trata de uma espécie sem valor comercial, é comumente devolvida ao mar quando a despesca da rede ocorre na água. Deste modo, é possível que a freqüência de ocorrência nos desembarques, desta e outras espécies sem valor comercial, subestime a real ocorrência das espécies na área de atuação das comunidades pesqueiras estudadas. Durante o inverno, a maior parte dos indivíduos de $N$. brasiliensis eram fêmeas adultas, menor parte eram fêmeas jovens e apenas um macho adulto foi observado (Figura 3). Na primavera, houve predomínio de fêmeas jovens em relação a adultas e o único macho examinado era jovem (Figura 3). No entanto, durante o verão, todas as fêmeas amostradas estavam grávidas. Nesta estação, a maioria dos machos era jovem e um era adulto. No outono poucos exemplares foram observados, sendo: uma fêmea adulta; um macho adulto e um macho neonato (Figura 3). Os dados obtidos sugerem que fêmeas grávidas de $N$. brasiliensis aproximam-se da costa durante o verão e realizam o parto, próximo ao outono. Estudos futuros poderão melhor explicar o ciclo reprodutivo de $N$. brasiliensis.

Rhinobatos percellens, raia de valor comercial, foi um dos elasmobrânquios mais presentes nos desembarques, ao longo de todos os períodos sazonais, sendo a espécie mais freqüente durante o verão (Figura 2). Durante o inverno e primavera, todas as fêmeas analisadas eram adultas, assim como a maioria dos machos, havendo também machos jovens (Figura 3). No verão, a maior parte das fêmeas adultas estava grávida (em início de gestação), algumas fêmeas eram jovens e todos os machos analisados eram adultos (Figura 3). Durante o outono, uma fêmea analisada estava grávida, em estágio final de gestação, com cinco embriões, CT médio = $16,2 \mathrm{~cm}$. Estes embriões apresentavam-se completamente formados e haviam consumido toda a reserva de vitelo. Parte dos embriões, estava exposta na cloaca da fêmea grávida, indicando tentativa de aborto, provocado pelo estresse da captura. Ainda durante o outono, outra fêmea capturada era adulta (não grávida) (Figura 3). O único macho analisado neste período era adulto. Não foram observados neonatos (Figura 3). Aparentemente, a gestação de R. percellens ocorre a partir do verão, e perdura até o outono, quando embriões completamente formados foram observados. É possível que o parto ocorra fora da área de estudo, uma vez que não foram observados neonatos. Os dados apresentados permitem concluir que $R$. percellens utiliza a área estudada, ao menos, durante parte de sua gestação. Estudo futuro sobre a biologia reprodutiva desta espécie deverá melhor explicar seu ciclo reprodutivo.
Zapteryx brevirostris, outra raia de valor comercial, foi o elasmobrânquio mais freqüente nos desembarques da primavera, sendo observada em todos os dias amostrados. Foi também, juntamente com $R$. percellens, a mais freqüente no inverno (Figura 2). Durante o outono, o único exemplar examinado era um macho adulto (Figura 3). No inverno, ocorreram apenas fêmeas e machos adultos e parte das fêmeas adultas estavam grávidas, em início de gestação (Figura 3). A freqüência de fêmeas grávidas aumentou durante a primavera e quase todas as fêmeas adultas continham embriões em seus ovidutos (Figura 3). Apenas uma fêmea jovem foi observada neste período e todos os machos amostrados eram adultos (Figura 3). No verão, quando a freqüência de ocorrência da espécie diminuiu nos desembarques, a proporção de fêmeas grávidas foi menor em relação à de fêmeas adultas não grávidas e, novamente, apenas machos adultos foram observados (Figura 3). Embora os embriões não tenham sido medidos, aparentemente o desenvolvimento foi progressivo, desde o inverno até o verão, quando foram observados os embriões mais desenvolvidos. Isto diferiu do observado por Batista (1991) no litoral do Rio de Janeiro, onde embriões ocorreram ao longo do ano e, em um mesmo período, em diferentes estágios de desenvolvimento. Como não foram capturados neonatos, no presente trabalho, é possível que o parto ocorra fora da área de estudo.

Rioraja agassizii esteve entre os elasmobrânquios mais freqüentes durante o inverno e a primavera (Figura 2). No inverno, a maioria das fêmeas era jovem, outras estavam grávidas e todos os machos analisados eram adultos (Figura 3). Durante a primavera, a freqüência de fêmeas adultas aumentou e a de jovens diminuiu (Figura 3). Neste período, maior parte das fêmeas adultas era constituída de grávidas e apenas machos adultos foram observados. No verão, apenas fêmeas jovens foram capturadas (Figura 3). É provável que as fêmeas grávidas capturadas durante a primavera estivessem em período de parto, uma vez que expeliam ovos plenamente formados.

Dasyatis americana foi rara nos desembarques (Figura 2) e ocorreu apenas durante a primavera, como fêmea jovem, e no verão, como macho jovem (Figura 3). Dasyatis guttata também foi rara (Figura 2) e ocorreu apenas no outono (macho jovem) e no inverno (fêmeas jovens) (Figura 3). Dasyatis hipostigma foi pouco mais freqüente que as outras espécies de Dasyatis e não foi observada apenas no outono (Figura 2). Fêmeas jovens foram observadas no inverno, jovens de ambos os sexos foram observados na primavera. Um macho adulto e dois jovens foram examinados no verão (Figura 3 ).

Gymnura altavela ocorreu apenas no verão e no inverno, sendo pouco mais freqüente no inverno (Figura 2). Todos os indivíduos analisados estavam no estágio jovem (Figura 3). No inverno, foram examinados fêmeas e um macho. No verão, foram observadas apenas fêmeas. 
Rhinoptera spp. foi, também, uma espécie rara nos desembarques. Ocorreu com maior freqüência apenas durante a primavera (Figura 2). Um macho jovem foi observado durante o inverno. Na primavera todas as fêmeas eram jovens e um macho era adulto, outro era jovem (Figura 3).

De acordo com Pereira \& Soares-Gomes (2002), a plataforma continental da região estudada atinge cerca de 200 km de largura e é levemente inclinada em direção ao talude, constituindo uma grande área para o desenvolvimento de espécies costeiras. Os dados do presente trabalho indicam a utilização da área estudada para o parto das espécies Galeocerdo cuvier (primavera), Rhizoprionodon lalandii (inverno e primavera), R. porosus (inverno e primavera), Sphyrna lewini (verão), Narcine brasiliensis (outono) e Rioraja agassizii (primavera). A captura de indivíduos jovens, em todos os períodos sazonais, evidencia que a área é utilizada durante o desenvolvimento de todas as espécies. A constatação de fêmeas com embriões ou fetos em diferentes estágios de desenvolvimento demonstra que a área estudada é também utilizada durante, pelo menos, parte da gestação de $R$. percellens (verão e outono) e Z. brevirostris (inverno, primavera e verão).

A captura de indivíduos neonatos, jovens e fêmeas grávidas é um fator preocupante da pesca artesanal. De acordo com Brander (1981) a sobrevivência dos jovens é muito importante para a manutenção das populações de elasmobrânquios, que sofrem pressão de pesca. Deste modo, é possível que a atividade pesqueira artesanal possa contribuir com a retirada de uma parcela significativa do recrutamento das espécies. É importante salientar que existem muitas comunidades pesqueiras artesanais ao longo das costas dos estados abordados no presente estudo. No entanto, os pescadores artesanais, freqüentemente, relataram que embarcações industriais atuam muito próximas à costa, certamente capturando as mesmas espécies, esgotando os recursos e até levando as redes de pesca artesanal. Assim, é sugerido que medidas, associadas a estudos prévios, que definam o real impacto causado por cada uma das frotas atuantes na região, sejam tomadas para proteger as espécies. No intuito de melhor administrar os recursos pesqueiros na região estudada, sugere-se a criação de uma área protegida de pesca, visto que restrições no uso de aparelhos de captura - por restringirem a captura de espécies de peixes teleósteos com valor comercial - trariam prejuízos e conflitos para as comunidades pesqueiras e, conseqüentemente, graves problemas sócio-econômicos.

\section{Agradecimentos}

Agradecemos aos pescadores de Barra do Saí e Brejatuba, por permitirem que seu trabalho fosse acompanhado; ao doutorando Maurício de Castro Robert, pelo auxílio prestado em campo, em laboratório e pelas sugestões; e ao CNPq, pelo auxílio financeiro.

\section{Referências Bibliográficas}

ABILHÔA, V. 1998. Composição e estrutura da ictiofauna em um banco areno-lodoso na Ilha do Mel, Paraná, Brasil. Dissertação de Mestrado, Zoologia/UFPR. 98p.

BARLETTA, M. \& CORRÊA, M.F.M. 1989. Chondrofauna do Complexo Estuarinos da Baía de Paranaguá e adjacências, PR. Levantamento e produtividade pesqueira. Resumos da IV Reunião do Grupo de Trabalho sobre Pesca e Pesquisa de Tubarões e Raias no Brasil. Tamandaré (PE), UFPE. pag 2.

BARLETTA, M. \& CORRÊA, M.F.M. 1991. Produtividade pesqueira da chondrofauna do complexo estuarino da Baía de Paranaguá e adjacências (PR - Brasil). Resumos da V Reunião do Grupo de Trabalho sobre Pesca e Pesquisa de Tubarões e Raias no Brasil. Santos (SP). pag 5.

BATISTA, V.S. 1991. Aspectos quantitativos da fecundidade e do desenvolvimento embrionário da raia Zapteryx brevirostris Muller \& Henle 1841 (Pisces, Rhinobatidae) da enseada de Itaipu, Niterói, Rio de Janeiro. Rev. Brasil. Biol., 51 (3): 495-501.

BRANDER, K. 1981. Disappearance of common skate Raia batis from Irish Sea. Nature, 290: 48-49.

CASTRO, J.L. 1983. Sharks of the North American Waters. Texas A \& M University Press. $1^{\text {st }}$ edition. 180p.

CHARVET, P. 1995a. Dados preliminares do levantamento da chondrofauna do litoral do Estado do Paraná. Resumos. VII Encontro do grupo de trabalho sobre pesca e pesquisa de tubarões e raias no Brasil, Rio Grande RS. pag 27.

CHARVET, P. 1995b. Pesca de elasmobrânquios juvenis no litoral do Estado do Paraná: uma realidade. Resumos. VII Encontro do grupo de trabalho sobre pesca e pesquisa de tubarões e raias no Brasil, Rio Grande - RS. pag 29.

CHAVES, P.T.C. \& CORRÊA, M.F.M. 1998. Composição ictiofaunística da área de manguezal da Baía de Guaratuba, Paraná, Brasil. Revta bras. Zool. 15(1):195202.

CHAVES, P.T.C., CORRÊA, C.E., ROBERT, M.C., COSTA, L., PICHLER, H.A., SOUZA, M.A., UMBRIA, S.C., GRANDO, GC. \& CALLUF, C. 2000. Análise comparativa dos grupos ictiofaunísticos dominantes em dois sistemas costeiros: estuário (Baía de Guaratuba) e plataforma continental (10-15 m), Estado do paraná, Brasil. Semana Nacional de Oceanografia, Univali, Itajaí. p482.

CHAVES, P.T.C \& ROBERT, M.C. 2003. Embarcações, artes e procedimentos da pesca no litoral Sul do Estado do Paraná, Brasil. Revista Atlântica, Rio Grande 25(1):53-59.

COMPAGNO, L.J.V. 1984. FAO species catalogue, Vol. 4, Sharks of the world. An annotated and illustrated catalogue of shark species known to date. Part 2, Carcharhiniformes. Fao Fish. Synop. 125(4/2): 251-655. 
CORRÊA, M.F.M. 1987. Ictiofauna da Baía de Paranaguá e adjacências (litoral do Estado do Paraná-Brasil): levantamento e produtividade. Dissertação de Mestrado, Zoologia/UFPR. 406p.

CORRÊA, M.F. \& MAEHAMA, O.K. 1988. Composição e variação temporal da ictiofauna para as regiões entre as Ilhas do Mel e da Cotinga e a foz do Rio Maciel (Baía de Paranaguá-PR-Brasil). Resumos do XV Congresso Brasileiro de Zoologia, Curitiba. pag 345.

FERREIRA, B.P. 1988. Ciclo reprodutivo de Rhizoprionodon lalandei (Valenciennes) e Rhizoprionodon porosus (Poey) (Selachii, Carcharinidae) na região de Barra de Guaratiba, RJ. An. Acad. bras. Ci., 60 (1): 91-101.

FIGUEIREDO, J.L. 1977. Manual de peixes marinhos do sudeste do Brasil. Vol. 1, Introdução. Cações, raias e quimeras, Universidade de São Paulo. 104p.

FROESE, R. \& PAULY, D. 2003. Editors. Fishbase. World Wide Web eletronic publication. www.fishbase.org, version 21 March 2004.

GADIG, O.B.F. 2001. Tubarões da costa brasileira. Tese de doutorado - Universidade Estadual Paulista, Instituto de Biociências de Rio Claro. 343p.

GODEFROID, R.S. 1997 Estrutura da comunidade de peixes da zona de arrebentação da praia de Pontal do Sul, Paraná, Brasil. Dissertação de Mestrado, Zoologia/UFPR. 130p.

HAZIN, F.H.V., FISCHER, A. \& BROADHURST, M.K. 2001. Aspects of reproductive biology of the scalloped hammerhead shark, Sphyrna lewini, off northeastern Brazil. Enviromental Biology of Fishes. 61:151-159.

IUCN. 2004. 2004 IUCN Red List of Threatened Species. $<$ www.redlist.org> $>$. Downloaded on 31 August 2005.

LOYOLA E SILVA, J. \& NAKAMURA, I.T. 1975. Produção do pescado no litoral paranaense. Acta Biol. Par. Curitiba, 4(3,4):75-119.

MAEHAMA, O.K. \& CORRÊA, M.F.M. 1987. Composição ictiofaunística par a zona de arrebentação de Pontal do Sul a Praia de Leste. Resumos do XIV Congresso Brasileiro de Zoologia, Juiz de Fora. pag 231.

MENEZES, N.A.; BUCKUP, P.A.; FIGUEIREDO, J.L. \& MOURA, R.L. 2003. (Editores.) Catálogo das espécies de peixes marinhos do Brasil. Museu de Zoologia da Universidade de São Paulo. 160p.

PAIVA, M.P. 1997. Recursos pesqueiros estuarinos e marinhos do Brasil. Fortaleza: EUFC. 278p.

PEREIRA, C. \& SOARES-GOMES, A. 2002. Biologia Marinha. Rio de Janeiro. Editora Interciência. 382p.

ROBERT, M.C. 2004. Análise da pesca artesanal de fundeio realizada pelas comunidades de Brejatuba, litoral sul do Paraná, e de Barra do Saí, litoral norte de Santa Catarina, Brasil. Dissertação de mestrado, Zoologia/UFPR. 125p.
RUSS, G.R. 1991. Coral reef fisheries: effects and yields. In The Ecology of Fishes on Coral Reefs, Ed. By P. F. Sale. Academic Press, San Diego. 601-635.

SANTOS, H.R.S. \& CARVALHO, M.R. 2004. Description of a new species of whiptailed stingray from the southwestern Atlantic Ocean (Chondrichthyes, Myliobatiformes, Dasyatidae). Bol. Mus. Nac., N.S., Zool. 516:1-24.

STEVENS, J.D., BONFIL, R., DULVY, N.K. \& WALKER, P.A. 2000. The effects of fishing on sharks, rays and chimaeras (chondrichthyans), and the implications for marine ecossystems. ICES Jorurnal of Marine Science. 57:476-494.

VOOREN, C.M. \& DA SILVA, K.G. 1991. On the taxonomy of the angel sharks from southern Brazil, with the description of Squatina occulta sp. n. Rev. Brasil. Biol., 51(3): 589-602.

Título: Elasmobrânquios capturados pela pesca artesanal na costa sul do Paraná e norte de Santa Catarina, Brasil.

Autores: Costa, L. and Chaves, P. T. C.

Biota Neotropica, Vol. 6 ( número 3): 2006

http://www.biotaneotropica.org.br/v6n3/pt/ abstract?article+bn02706032006

Recebido: 25/09/2005

Publicado: 16/11/2006

ISSN 1676-0603 